\title{
Oropharyngeal Colonization With Neisseria lactamica, Other Nonpathogenic Neisseria Species and Moraxella catarrhalis Among Young Healthy Children in Ahvaz, Iran
}

\author{
Raheleh Sheikhi ${ }^{1,2}$; Mansour Amin ${ }^{1,2,} ;$;Soodabeh Rostami ${ }^{3}$;Saeed Shoja ${ }^{2}$; Nasim Ebrahimi ${ }^{2}$ \\ ${ }_{1}^{1}$ Health Research Institute, Infectious and Tropical Diseases Research Center, Jundishapur University of Medical Sciences, Ahvaz, IR Iran \\ ${ }_{3}^{2}$ Department of Microbiology, Jundishapur University of Medical Sciences, Ahvaz, IR Iran \\ 3 Infectious Diseases and Tropical Medicine Research Center, Isfahan University of Medical Sciences, Isfahan, IR Iran \\ *Corresponding author: Mansoor Amin, Department of Microbiology, School of Medicine, Ahvaz Jundishapur University of Medical Sciences, Ahvaz, IR Iran. Tel: +98-6113367543, Fax: \\ +98-6113332036, E-mail: mnsamin@yahoo.com
}

Received: September 13, 2013; Revised: December 20, 2013; Accepted: January 5, 2014

\begin{abstract}
Background: Neisseria lactamica as one of the main commensal in oropharynx during the childhood is related to the induction of a natural immunity against meningococcal meningitis. Also Moraxella catarrhalis in oropharynx of children is a predisposing factor for otitis media infection.

Objectives: The current study aimed to investigate the frequency of the N. lactamica, other nonpathogenic Neisseria spp. and M. catarrhalis in the oropharynx of young healthy children in Ahvaz, Iran by the two phenotypic tests and Polymerase Chain Reaction (PCR).

Materials and Methods: A total of 192 oropharyngeal swab samples of the young healthy children were studied during four months. Swabs were plated onto enriched selective media and non-selective media. Gram-negative and oxidase-positive diplococci were identified by several conventional biochemical tests. The PCR and sequencing were used to confirm the accuracy of laboratory diagnosis to identify N. lactamica and M. catarrhalis.

Results: Among 192 young healthy children with the mean age of $5.93 \pm 2.5903$ years, authors identified: $N$. lactamica (21.9\%) in the age group of one to nine years; $N$. mucosa (6.3\%); $N$. sicca (7.8\%); N. cinerea (1.6\%); N. subflava (biovar subflava) (4.2\%); N. subflava (biovar perflava) (28.1\%); N. subflava (biovar flava) (7.3\%) and M. catarrhalis (42.7\%).

Conclusions: The young healthy children screening by colonization of N. lactamica and other nonpathogenic Neisseria spp. in oropharynx was the first report in Ahvaz, Iran. The study results demonstrated the high frequency of colonization of M. catarrhalis in the studied young healthy children other than Neisseria spp.
\end{abstract}

Keywords:Neisseria lactamica; Moraxella catarrhalis; Colonization; Child

\section{Background}

The genera of Neisseria and Moraxella include Gramnegative and oxidase-positive diplococci that are mostly isolated from the upper respiratory tract of humans (1, 2). Neisseria lactamica is a commensal species, which is colonized more frequently in the oropharynges of young children than those of the adults, and the colonization rate decreases with age increase (2-6). Among nonpathogenic Neisseria species, $N$. lactamica shows close antigenic similarities with $\mathrm{N}$. meningitides. Yazdankhah et al. demonstrated that the carriage of $N$. lactamica is associated with a high titer of antibodies against N. meningitides (7). Previous studies showed that the development of cross-protective immunity against $\mathrm{N}$. meningitides is observed in $N$. lactamica carriers. Therefore, it is proposed that colonization with $\mathrm{N}$. lactamica during early childhood will protect the host against the colonization with $\mathrm{N}$. meningitides by natural immunity $(2,3,8,9)$. Local monitoring of the colonization due to N. lactamica in the young children should be considered to learn about the immunity of these children to the life-threatening meningococcal infection. Investigation of the $N$. lactamica carriage rate is rarely performed on a frequent basis in the healthy children in Iran (10). Epidemiological and regional evaluation of nonpathogenic Neisseria species should be considered in the future studies. There is no information about the frequency of nonpathogenic Neisseria species in children living in the area under study.

Moraxella catarrhalis is part of the commensal species in the upper respiratory tract of approximately $7 \%$ to $36 \%$ of the healthy children, but decreases substantially in adulthood. Otitis media is an infection of the upper respiratory tract in children that is closely related to the colonization of $M$. catarrhalis. Therefore, colonization of M. catarrhalis in the healthy carriers may be as a predisposing factor for otitis media and is now firmly established as an etiological cause of otitis media (11-13). Therefore, the high colonization rate of $M$. catarrhalis in oropharynx during the

Copyright (C) 2015, Ahvaz Jundishapur University of Medical Sciences. This is an open-access article distributed under the terms of the Creative Commons Attribution-NonCommercial 4.0 International License (http://creativecommons.org/licenses/by-nc/4.0/) which permits copy and redistribute the material just in noncommercial usages, provided the original work is properly cited. 
childhood is related to the high sensitivity to the otitis media infection. Surveys on M. catarrhalis carriage rates among young healthy children are rarely performed in Iran $(14,15)$.

\section{Objectives}

The current study aimed to investigate the frequency of $N$. lactamica, other nonpathogenic Neisseria species, and M. catarrhalis such as Gram-negative, oxidase-positive diplococci in the oropharynges of young healthy children in Ahvaz, Iran by the two phenotypic tests and Polymerase Chain Reaction (PCR).

\section{Materials and Methods}

\subsection{Oropharyngeal Sampling}

A total of 192 young normal healthy children from some kindergartens, preschool and schools of Ahvaz city were studied from November 2012 to March 2013. The healthy children under 10 without any respiratory infections were eligible for inclusion. The present study was approved by the Ahvaz Jundishapur University of Medical Sciences Ethics Committee (code number: ETH609). The oropharyngeal samples were obtained from children `s oropharynx by sterile Dacron swab. The pharyngeal swabs were inoculated directly onto the Modified Thayer-Martin medium (MTM agar), including GC gonococcal agar supplemented with Vitox, hemoglobin powder, vancomycin, colistin, trimethoprim and nystatin (Oxoid,
Basingstoke, UK). Plates were incubated at $37^{\circ} \mathrm{C}$ in a $5 \% \mathrm{CO}_{2}$ atmosphere and investigated after 48 hours. Oxidase-positive and Gram-negative diplococci were isolated for the present study. The pure colonies were stored in skimmed milk broth (Sigma Aldrich, USA) with 10\% (v/v) glycerol at $-80^{\circ} \mathrm{C}$ for later use.

\subsection{Identification of Isolated Strains}

Gram-negative and oxidase-positive diplococci were identified by their patterns of growth in different culture media and several biochemical tests shown in Table 1(16).

Identification of $N$. lactamica may be confirmed by detecting beta-galactosidase in an enzyme substrate test. Therefore, $\beta$-galactosidase activity was tested with o-nitrophenyl- $\beta$-D-galactopyranoside disc (ONPG) (Rosco Diagnostica, Denmark) as the substrate. ONPG test was performed according to the manufacturer's instructions. ONPG-positive isolates were yellow after incubation at $37^{\circ} \mathrm{C}$ for more than one hour (17). Furthermore, superoxol (30\% hydrogen peroxide [H202]) test was performed after incubation of the test isolate on BrainHeart Infusion (BHI) agar (Merck, Germany) for 24 hours. $N$. lactamica usually produces weak brisk bubbling with delayed bubbling (16). Identification of M. catarrhalis may be confirmed by Deoxyribonuclease (DNase) activity $(16,18,19)$.

Identification of other nonpathogenic Neisseria species are based on their patterns of growth in different culture media and biochemical tests (16). All of the diagnostic tests were performed three times for each sample.

\begin{tabular}{|c|c|c|c|c|c|c|c|c|c|c|c|}
\hline \multirow[t]{2}{*}{ Species } & \multirow{2}{*}{$\begin{array}{c}\text { No. (\%) } \\
=192\end{array}$} & \multicolumn{4}{|c|}{ Acid produced from } & \multirow{2}{*}{$\begin{array}{l}\text { Polysac-charide Reduction Pigment } \\
\text { Produced from of NO3 } \\
5 \% \text { sucrose }\end{array}$} & \multicolumn{4}{|c|}{ Growth on } & \multirow[t]{2}{*}{ DNase } \\
\hline & & Glu-cose Mal-tose & $\begin{array}{l}\text { Lactose } \\
\text { (ONPG) }\end{array}$ & $\begin{array}{l}\text { Suc- } \\
\text { rose }\end{array}$ & $\begin{array}{c}\text { Fruc- } \\
\text { tose }\end{array}$ & & $\begin{array}{c}\text { MTM } \\
\text { medium }\end{array}$ & $\begin{array}{l}\text { Blood } \\
\text { agar at } \\
22^{\circ} \mathrm{C}\end{array}$ & $\begin{array}{l}\text { Blood } \\
\text { agar at } \\
37^{\circ} \mathrm{C}\end{array}$ & $\begin{array}{l}\text { Nutrient } \\
\text { agar at } \\
37^{\circ} \mathrm{C}\end{array}$ & \\
\hline
\end{tabular}

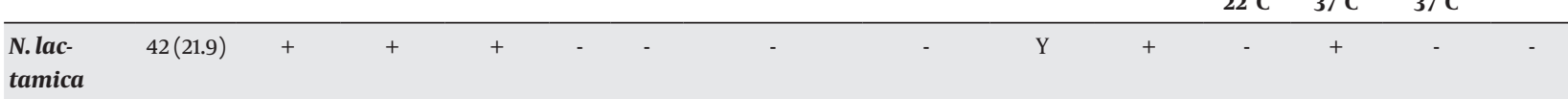

\begin{tabular}{|c|c|c|c|c|c|c|c|c|c|c|c|c|c|c|}
\hline N. mucosa & $12(6.3)$ & + & + & - & + & + & + & + & slY & - & + & + & + & - \\
\hline N. sicca & $15(7.8)$ & + & + & - & + & + & + & - & - & - & + & + & + & - \\
\hline N. cinerea & $3(1.6)$ & - & - & - & - & - & - & - & G & $+\mathrm{w}$ & - & - & - & - \\
\hline \multicolumn{15}{|l|}{ N. subflava } \\
\hline $\begin{array}{l}\text { Biovar } \\
\text { subflava }\end{array}$ & $8(4.2)$ & + & + & - & - & - & - & - & $\mathrm{Y}$ & - & + & + & + & - \\
\hline $\begin{array}{l}\text { Biovar } \\
\text { perflava }\end{array}$ & $54(28.1)$ & + & + & - & + & + & + & - & $\mathrm{Y}$ & $+\mathrm{w}$ & + & + & + & - \\
\hline $\begin{array}{l}\text { Biovar } \\
\text { flava }\end{array}$ & $14(7.3)$ & + & + & - & - & + & - & - & $\mathrm{Y}$ & - & + & + & + & - \\
\hline M. & $82(42.7)$ & - & - & - & - & - & - & + & $\mathrm{p}$ & $+\mathrm{w}$ & + & + & + & + \\
\hline
\end{tabular}

\footnotetext{
a All species were oxidase-positive, catalase $\left(3 \% \mathrm{H}_{2} \mathrm{O}_{2}\right)$-positive.

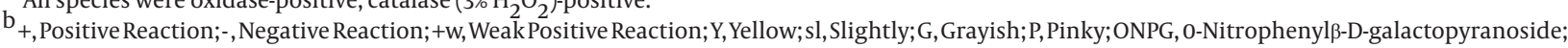
MTM, Modified Thayer-Martin.
} 
Sheikhi R et al.

Table 2. Oligonucleotides and Polymerase Chain Reaction Condition

\begin{tabular}{|c|c|c|c|c|c|}
\hline $\begin{array}{l}\text { Oligonu- } \\
\text { cleotide }\end{array}$ & Sequence & Gene Amplified & $\begin{array}{l}\text { Amplicon Length } \\
\text { (base pair) }\end{array}$ & PCR condition for two species & Reference \\
\hline NL1 & 5'-AATGTTTGGACGGCGACTAC-3' & $p d h C$ & 161 & \multirow{4}{*}{$\begin{array}{c}94^{\circ} \mathrm{C} / 5 \mathrm{~min}, 57^{\circ} \mathrm{C} / 45 \mathrm{sec}, 72^{\circ} \mathrm{C} / 45 \mathrm{sec}, \\
35 \mathrm{cycles} \text { of }\left(94^{\circ} \mathrm{C} / 45 \mathrm{sec}, 57^{\circ} \mathrm{C} / 45 \mathrm{sec},\right. \\
72^{\circ} \mathrm{C} / 45 \mathrm{sec} \text { and elongation } 72^{\circ} \mathrm{C} \text { for } \\
5 \mathrm{~min}\end{array}$} & This study \\
\hline NL2 & 5'-GTACACTTTTTGCGGGTCGT-3' & & & & \\
\hline MCAT1 & 5'-TTGGCTTGTGCTAAAATATC-3' & glyRS & 140 & & $(20)$ \\
\hline MCAT2 & 5'-GTCATCGCTATCATTCACCT-3' & & & & \\
\hline
\end{tabular}

\subsection{Molecular Characterization}

\subsubsection{DNA extraction.}

Chromosomal DNA of $N$. lactamica and M. catarrhalis isolated strains were extracted by the boiling method. Extracted DNA samples were stored at $-20^{\circ} \mathrm{C}$ for later use.

\subsubsection{Polymerase Chain Reaction (PCR)}

All of the N. lactamica and M. catarrhalis isolates were tested by PCR for the presence of $p d h C$ (6) and glyRS (20) genes; respectively. To evaluate glyRS gene, the primers previously described by Post et al. were used, and to evaluate $p d h C$ gene, newly designed primers were applied (Table 2). Primers were purchased from TAG Copenhagen A/S, Denmark. In each assay, the final $25 \mu \mathrm{L}$ reaction mixture contained $2.5 \mu \mathrm{L}$ of the $10 \times$ reaction buffer; $1 \mu \mathrm{L}$ of $50 \mathrm{mM} \mathrm{MgCl} 2$; $0.5 \mu \mathrm{L}$ of $2.5 \mathrm{mM}$ dNTPs; $0.5 \mu \mathrm{L}$ of each primer $(20 \mathrm{pmol} / \mu \mathrm{L}) ; 0.2 \mu \mathrm{L}$ Taq polymerase $(5 \mathrm{U} / \mu \mathrm{L})$; and $18.8 \mu \mathrm{L}$ sterile distilled water. The PCR assays were performed in a Mastercycler Eppendorf (Eppendorf, Germany). Amplicons were analyzed by electrophoresis on a 1.5\% agarose gel. PCR products were visualized and photographed under ultraviolet illumination. All the chemical materials used in this study were purchased from CinnaGen, Iran. Two reference strains were used as controls: N. lactamica (ATCC 23970) and M. catarrhalis (ATCC 25240). The results were analyzed using the SPSS software version 19.

\section{Results}

The carriage of N. lactamica, other nonpathogenic Neisseria spp. and M. catarrhalis were studied in a total of 192 young healthy children with the mean age of $5.93 \pm 2.5903$ year, including 106 (55.2\%) male and 86 (44.8\%) female in Ahvaz, Iran, from November 2012 to March 2013. All of the Gram-negative and oxidase-catalase positive diplococci were investigated by several biochemical tests and cultural characteristics as shown in Table 1. N. lactamica colonies were $>50 \mathrm{CFU}$ and $M$. catarrhalis colonies $\leq 10 \mathrm{CFU}$ on MTM medium. The most common bacteria isolated from the oropharynx were $M$. catarrhalis $(42.7 \%, \mathrm{n}=82)$, N. subflava Biovar perflava $(28.1 \%, \mathrm{n}=54)$ and $N$. lactamica (21.9\%, $n=42)$, respectively. In some of the oropharyngeal
Figure 1. PCR Amplification
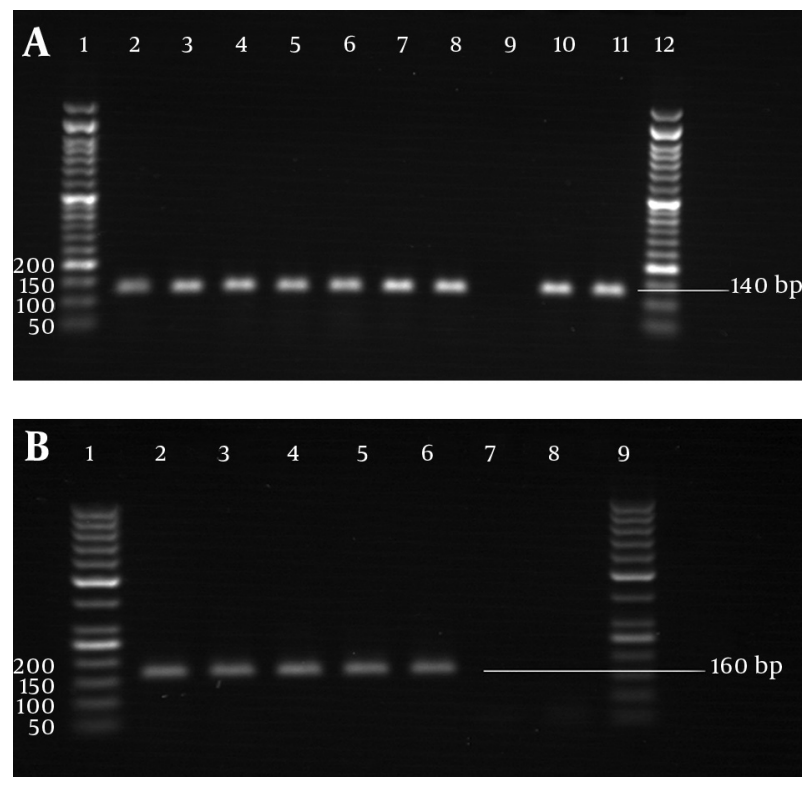

A) glyRS gene of $M$. catarrhalis strains. Lanes 2-8, isolated strains; lane 9 , negative control; lanes 10-11, standard strains; lanes 1 and 12; 50 bp DNA marker. B) pdhC gene of $N$. lactamica strains. Lane 2, standard strain; lanes 3-6, isolated strains; lanes 7-8, negative controls; lanes 1 and 9, 50 bp DNA marker

swab samples at least two Neisseria species were identified with the same subject. Also, some of the biochemical properties and the colony shape of the Neisseria species were similar which could lead to misdiagnosis, and sometimes two different species were recognized as one.

PCR analysis was performed for all the N. lactamica and $M$. catarrhalis isolates. Amplified products of $p d h C$ and glyRS genes underwent bidirectional sequencing by the ABI 3730XL DNA Analyzer (Applied Biosystems, USA). The sequences of the $p d h C$ and glyRS genes were entered into a BLAST search (http://blast.ncbi.nlm.nih.gov/Blast.cgi). Multiple sequence alignments were performed with the MEGA (version 4). Comparing the sequence of PCR product of $p d h C$ gene with that of registered in GeneBank confirmed a new sequence, in one of the isolates (NL2) (accession no. HG416927). Also the sequence of glyRS gene PCR product confirmed the accuracy of PCR results. 


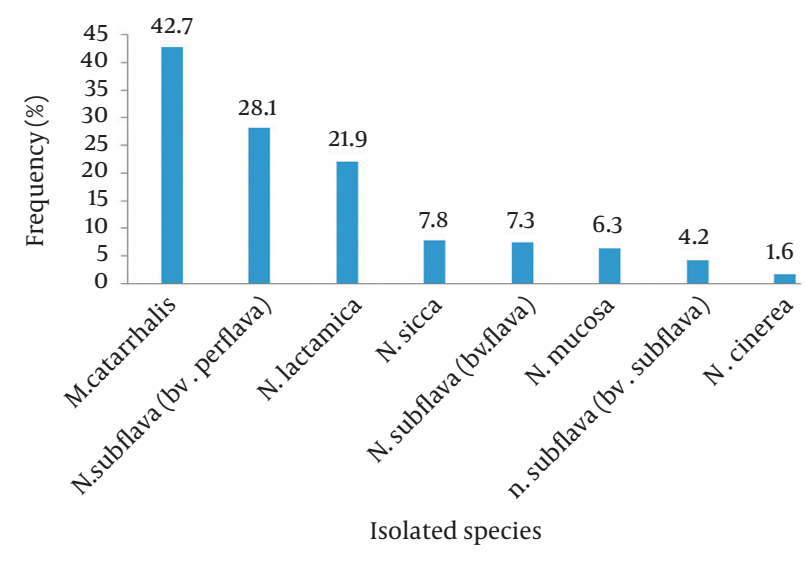

Figure 2. Frequency of the Isolated Species in Oropharynx of the Studied Children

\section{Discussion}

Oropharyngeal colonization by oxidase-positive and Gram-negative diplococci in young healthy children should be considered in Iran, because there are only a few studies have been conducted in this regard. In contrast to the results of the current study, Pourmand et al. reported $3 \%$ N. lactamica among 364 of the healthy children aged 1012 years old in Tehran (10). As mentioned above, the studied bacterial species are colonized more frequently in the oropharynx of young children and colonization rate decreases with the age increase (2-6). Results of the study by Fahimzad et al. were similar to those of the current study. They showed a frequency of M. catarrhalis (13.5\%) colonization in the oropharynx of 296 healthy children aged 2-6 years old (14). In another study, Bakhshaee et al. demonstrated that exposure to tobacco smoke significantly increased the carriage rate of $M$. catarrhalis in children (15). There are no reference data available on the isolation of nonpathogenic Neisseria spp. in Iran.

Evans et al. showed that some individuals are intrinsically resistant to $N$. lactamica carriage and also other reports mentioned that colonization peak of $N$. lactamica in the upper respiratory tract increases $21 \%$ at 18 months of age, followed by a decrease to $1.8 \%$ by the age of 14 to 17 years $(6,16)$. In the current study, the frequency of $N$. lactamica was $21.9 \%$ in young children aged one to nine years old. Similar to the obtained results (Figure 2), Saez Nieto et al.(21) found N. subflava (biovar perflava) with the highest $(28.1 \%)$ and $N$. cinerea with the lowest (1.6\%) frequency in the oropharynx of young children. Also the prevalence of $M$. catarrhalis (42.7\%) was considerable more than any other Neisseria species. Ejlertsen et al. showed that a high rate of colonization is associated with an increased risk of otitis media (22). No significant relationship was found between the gender and bacterial colonization in the current study. Also, the sampling time (month of sampling) had no effect on the bacterial colonization, since these or- ganisms are commensal in the upper respiratory tract of children, especially N. lactamica and M. catarrhalis.

Neisseria species are very susceptible to environmental changes compared to $M$. catarrhalis. Therefore, they may be lost in the process of diagnosis. Furthermore, they may overgrow in the primary isolation by the other microflora in the upper respiratory tract (21). In addition, Neisseria species and M. catarrhalis are not colonized only in the oropharynx. The results of the current study showed that Neisseria spp. and M. catarrhalis were not isolated from all of the studied subjects. Hence, to evaluate the reliable frequency of Neisseria species and M. catarrhalis in pharynx, other identification techniques are necessary to obtain accurate results. $N$. lactamica is colonized more frequently in the oropharynges of young children. There are numerous reports illustrating that carriage of $N$. lactamica may assist in the development of natural cross-protective immunity to $N$. meningitidis serogroup B strains, the cause of life-threatening bacterial meningitis $(3,8,9,17,23-25)$. Therefore, screening the young children for $N$. lactamica in their upper respiratory tract is very important to determine the susceptibility to meningococcal meningitis.

In conclusion, the present study was the first report from Ahvaz, Iran, and demonstrated that the rate of colonization and success in detecting the living bacteria in the upper respiratory tract was influenced not only by age but also by site of colonization and sampling, physiology of bacteria, genetic, and host immune system.

\section{Acknowledgements}

This work is a part of Ph.D thesis of Raheleh Sheikhi which has been approved in the Department of Microbiology of Ahvaz Jundishapur University of Medical Sciences, Ahvaz. Iran. The authors thank the Health Research Institute, Infectious and Tropical Diseases Research Center, Jundishapur University of Medical Sciences, Ahvaz, Iran for financial support (grant No. 91124). We specially thank staff of Department of Microbiology for their great supports.

\section{Authors' Contribution}

Raheleh Sheikhi (All parts of the research), Mansour Amin (All parts of the research and revising the manuscript), Soodabeh Rostami (PCR performance and analysis), Saeed Shoja (PCR performance and analysis), Nasim Ebrahimi (collection of samples)

\section{Financial Disclosure}

This study was supported by a grant from Health Research Institute, Infections and Tropical Diseases Research Center, Jundishapur University of Medical Sciences, Ahvaz, Iran (No. 91124).

\section{Funding/Support}


This research was financially supported by Health Research Institute, Infections and Tropical Diseases Research Centre, Jundishapur University of Medical Sciences, Ahvaz, Iran, and Department of Microbiology of Ahvaz Jundishapur University of Medical Sciences, Ahvaz, Iran

\section{References}

1. Bennett JS, Griffiths DT, McCarthy ND, Sleeman KL, Jolley KA, Crook DW, et al. Genetic diversity and carriage dynamics of Neisseria lactamica in infants. Infect Immun. 2005;73(4):2424-32.

2. Li Y, Zhang Q, Winterbotham M, Mowe E, Gorringe A, Tang CM. Immunization with live Neisseria lactamica protects mice against meningococcal challenge and can elicit serum bactericidal antibodies. Infect Immun. 2006;74(11):6348-55.

3. Tunes CF, Ferraz AS, Scola MCG, De Gaspari EN. Intranasal delivery of whole cells of neisseria species: study of cross-reactive antigens in rabbits. Open Vaccine J. 2008;1:13-21.

4. Bennett JS, Bentley SD, Vernikos GS, Quail MA, Cherevach I, White $\mathrm{B}$, et al. Independent evolution of the core and accessory gene sets in the genus Neisseria: insights gained from the genome of Neisseria lactamica isolate 020-06. BMC Genomics. 2010;11:652.

5. Bennett JS, Callaghan MJ, Derrick JP, Maiden MC. Variation in the Neisseria lactamica porin, and its relationship to meningococcal PorB. Microbiology. 2008;154(Pt 5):1525-34.

6. Evans CM, Pratt CB, Matheson M, Vaughan TE, Findlow J, Borrow $\mathrm{R}$, et al. Nasopharyngeal colonization by Neisseria lactamica and induction of protective immunity against Neisseria meningitidis. Clin Infect Dis. 2011;52(1):70-7.

7. Yazdankhah SP, Caugant DA. Neisseria meningitidis: an overview of the carriage state. J Med Microbiol. 2004;53(Pt 9):821-32.

8. Abel A, Sanchez S, Arenas J, Criado MT, Ferreiros CM. Bioinformatic analysis of outer membrane proteome of Neisseria meningitidis and Neisseria lactamica. Int Microbiol. 2007;10(1):5-11.

9. Finney M, Vaughan T, Taylor S, Hudson MJ, Pratt C, Wheeler JX, et al. Characterization of the key antigenic components and preclinical immune responses to a meningococcal disease vaccine based on Neisseria lactamica outer membrane vesicles. Hum Vaccin. 2008;4(1):23-30.

10. Pourmand MR, Sadighian H, Abdossamdi Z. Frequency of pharyngeal Neisseria Carriage among 10-12 years old pupiles in Tehran, Iran. J Gorgan Univ Med Sci. 2011;13(3):72-7.

11. Verhaegh SJ, Snippe ML, Levy F, Verbrugh HA, Jaddoe VW, Hofman A, et al. Colonization of healthy children by Moraxella catarrhalis is characterized by genotype heterogeneity, virulence gene diversity and co-colonization with Haemophilus influenzae. Mi- crobiology. 2011;157(Pt 1):169-78.

12. de Vries SP, van Hijum SA, Schueler W, Riesbeck K, Hays JP, Hermans PW, et al. Genome analysis of Moraxella catarrhalis strain $\mathrm{BBH} 18$, [corrected] a human respiratory tract pathogen. J Bacteriol. 2010;192(14):3574-83.

13. Murphy TF. Moraxella catarrhalis, Kingella, and Other Gram-Negative Cocci. In: Mandell GL, Bennett JE, Dolin R editors. Mandell, Douglas, and Bennett's principles and practice of infectious diseases: Churchill Livingstone/Elsevier; 2010.

14. Fahimzad A, Karimi B, Malekan MA, Shamshiri AR, Mohkam M, Sharifian $M$, et al. Prevalence of variant bacteria in oropharyngeal colonization of Iranian children. Arc Clin Infec Dis. 2008;3(1).

15. Bakhshaee M, Naderi HR, Ghazvini K, Sotoudeh K, Amali A Ashtiani SJ. Passive smoking and nasopharyngeal colonization by Streptococcus pneumoniae, Haemophilus influenzae, and Moraxella catarrhalis in daycare children. Eur Arch Otorhinolaryngol.2012;269(4):1127-32.

16. Winn WC, Koneman EW. Koneman's Color Atlas and Textbook of Diagnostic Microbiology:: Lippincott Williams \& Wilkins; 2006.

17. Alber D, Oberkotter M, Suerbaum S, Claus H, Frosch M, Vogel U. Genetic diversity of Neisseria lactamica strains from epidemiologically defined carriers. J Clin Microbiol. 2001;39(5):1710-5.

18. Murphy TF, Parameswaran GI. Moraxella catarrhalis, a human respiratory tract pathogen. Clin Infect Dis. 2009;49(1):124-31.

19. Ahmad F, Young H, McLeod DT, Croughan MJ, Calder MA. Characterisation of Branhamella catarrhalis and differentiation from Neisseria species in a diagnostic laboratory. J Clin Pathol. 1987;40(11):1369-73.

20. Post JC, Preston RA, Aul JJ, Larkins-Pettigrew M, Rydquist-White J, Anderson KW, et al. Molecular analysis of bacterial pathogens in otitis media with effusion. JAMA.1995;273(20):1598-604.

21. Saez Nieto JA, Marcos C, Vindel A. Multicolonization of human nasopharynx due to Neisseria spp. Int Microbiol.1998;1(1):59-63.

22. Ejlertsen T, Thisted E, Ebbesen F, Olesen B, Renneberg J. Branhamella catarrhalis in children and adults. A study of prevalence, time of colonisation, and association with upper and lower respiratory tract infections. J Infect. 1994;29(1):23-31.

23. Oliver KJ, Reddin KM, Bracegirdle P, Hudson MJ, Borrow R, Feavers IM, et al. Neisseria lactamica protects against experimental meningococcal infection. Infect Immun. 2002;70(7):3621-6.

24. Trotter C, Findlow J, Balmer P, Holland A, Barchha R, Hamer N, et al. Seroprevalence of bactericidal and anti-outer membrane vesicle antibodies to Neisseria meningitidis group B in England. Clin Vaccine Immunol. 2007;14(7):863-8.

25. Sanchez S, Troncoso G, Ferreiros CM, Criado MT. Evaluation of cross-reactive antigens as determinants of cross-bactericidal activity in pathogenic and commensal Neisseria. Vaccine. 2001;19(25-26):3390-8. 